\title{
Lower cost automotive piston from 2124/SiC/25p metal-matrix composite
}

\author{
J. Falsafi ${ }^{a}$, M. Rosochowska ${ }^{a}$, P. Jadhav ${ }^{a}$, D. Tricker ${ }^{b}$ \\ a Advanced Forming Research Centre, University of Strathclyde, Inchinnan, Renfrew, PA4 9LJ, UK \\ ${ }^{\mathrm{b}}$ Materion Aerospace Metal Composites, Farnborough, Hampshire, GUI4 6XE, UK
}

\begin{abstract}
Engineered materials have made a breakthrough in a quest for materials with a combination of custom-made properties to suit particular applications. One of such materials is $2124 / \mathrm{SiC} / 25 \mathrm{p}$, a high-quality aerospace grade aluminium alloy reinforced with ultrafine particles of silicon carbide, manufactured by a powder metallurgy route. This aluminium matrix composite offers a combination of greater fatigue strength at elevated temperatures, lower thermal expansion and greater wear resistance in comparison with conventionally used piston materials. The microscale particulate reinforcement also offers good formability and machinability. Despite the benefits, the higher manufacturing cost often limits their usage in high-volume industries such as automotive where such materials could significantly improve the engine performance. This paper presents mechanical and forging data for a lower cost processing route for metal matrix composites. Finite element modelling and analysis were used to examine forging of an automotive piston and die wear. This showed that selection of the forging route is important to maximise die life. Mechanical testing of the forged material showed a minimal reduction in fatigue properties at the piston operating temperature.
\end{abstract}

\section{Introduction}

Metal-Matrix Composites (MMC) offer attractive features to automotive engineers and designers to meet the current and future challenges for improved performance, fuel-efficient, and lowemission vehicles. Properties of these materials can be tailored to meet specific design requirements of various powertrain or chassis components. Compared to conventional materials MMCs provide a high strength-to-weight ratio, enhanced mechanical and thermal characteristics, improved fatigue and fracture properties, as well as excellent wear resistance [1]. Metal matrix composites are mainly used to produce engineering components for aerospace and electronics industry or custom products for racing cars. Applications in the automotive sector are limited to a few engine components such as drive shafts or brake components. Since the automotive industry is a highly cost-sensitive sector thus the high cost of composites and required infrastructures restricts the application of these materials [2].

One of the advanced materials to replace conventional structural alloys is a high-grade aluminium alloy AA2124 reinforced with ultrafine particles of silicon carbide. Its high strength, fatigue resistance and hardness at elevated temperatures make this composite a successful candidate for automotive engine components such as valve train, pistons, cylinder liners or connecting rods [3], [4]. Properties of this composite such as strain hardening at different temperatures are reported in [5] while the behaviour under monotonic and cyclic loading conditions in [6], [7]. Wear resistance of this material has been reported to be higher than other AA2124 matrix composites [8]. Another important feature of this material is the high specific modulus, defined as a ratio of Young's modulus to the mass density of the material, which is a key engineering attribute when designing for minimum structural weight is crucial. Materials with a high specific modulus are important in Aerospace, Automotive and Robotic systems. Figure 1 compares specific modulus of $2124 / \mathrm{SiC} / 25 \mathrm{p}$ with that of other common alloys.

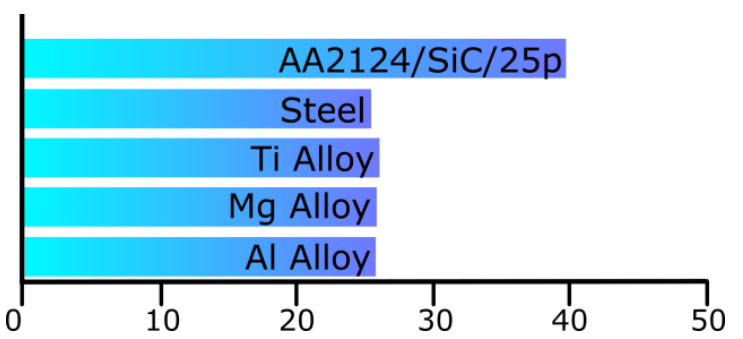

Figure 1. Specific modulus of 2124/SiC/25p Vs other common alloys [9].

$2124 / \mathrm{SiC} / 25 \mathrm{p}$ is produced using the powder metallurgy (PM) technology involving multiple operations; this makes this material expensive. However, this process is considered to be green as PM process releases very little fumes and chemicals to the atmosphere [10]. Further, there are two factors which can increase the potential of implementing this technology in high volume automotive manufacturing. The first is the opportunity to produce $\mathrm{Al} / \mathrm{SiC}$ composite through a lower cost route. And the second is a higher production rate at a reduced cost and minimum material waste. The latter may be achieved by using a precision hot forging technology to manufacture components. Precision forging is described as a nearnet-shape forging operation that produces high-quality parts regarding the surface quality and dimensional accuracy. A shorter production cycle due to minimal post-forge machining and a reduced material waste contribute to the cost reduction while meeting regulatory requirements and competitive pressures. The forging technology is particularly suitable for the production of high duty components such as pistons. Components forged from the $\mathrm{Al} / \mathrm{SiC}$ composite shows higher tensile strengths and ductility than the cast components [11]. Further, this composite has been reported to have excellent forgeability [12] that allows forging of parts with complex geometry free of cracks in one forging operation. 
This paper addresses some aspects of the precision hot forging of an automotive piston from $2124 / \mathrm{SiC} / 25$ p composite manufactured using the lower cost route developed by Materion AMC.

In hot forging, the cost of tools accounts for a substantial fraction of the overall production cost. This is of particular significance in the closed die forging where the stresses in the tools can reach a high level at the final forming stage which may lead to the premature die wear/damage. This aspect has also been investigated and is presented in this paper.

\section{Particle reinforced $\mathrm{Al}$ alloy 2124/SiC}

Particulate reinforced aluminium alloys are discontinuous reinforced metal-matrix composites, in which the addition of ceramic particles, to aluminium alloys through PM techniques creates a new class of materials with advantageous properties. Unlike continuous metalmatrix composites, these materials with discrete reinforcing particles within the parent alloy matrix, have been found to be workable by all existing metalworking techniques, including hot forging. Such feature makes these composites very attractive for a wide range of industrial applications. One of the discontinuous metal-matrix composite alloy based on $2 \mathrm{xxx}$ series which has become commercially available is $2124 / \mathrm{SiC} / 25 \mathrm{p}$ [13]. The presence of reinforcement within the matrix; typically 10 to $40 \%$ in volume, leads to a significant modification of the characteristics of the parent alloy such as an increase in elastic modulus, strength and abrasion resistance, and improved properties at elevated temperatures. On the downside, reduction in ductility and fracture toughness is a design obstacle [14], [15].

The addition of particulate reinforcing to ductile alloy matrix also modifies the deformation behaviour and changes the flow stress [13], [16], [17]. At forging temperatures above $425^{\circ} \mathrm{C}$, for instance, flow stress is lower than monotonic 2124 . The fabrication history of this material can also significantly impact the deformation in hot forging and development of the final mechanical property [18]. In other words, the process route is specified depending on the required mechanical property, component shape and cost constraints. The billet temperature for forging such materials has to be specified case by case, however typically temperatures higher than those used for their matrix alloys are necessary.

Forging programs have shown that MMCs based on the 2xxx series aluminium alloys can be successfully forged using high-definition closed-die forgings. The forged composite shows good mechanical strength and ductility [19]. Good hot formability of such composites is due to the small size of $\mathrm{SiC}$ reinforcement particles [12]. Some evidence suggests that these composites are more aggressive on closed-die tooling and that the die life in forging these materials may be shorter than that of a die used to forge their parent alloys [20][22].

2124/SiC/25p is manufactured through a special PM route to minimise a chemical reaction between metal matrix and ceramic particulates, ensuring the purity of the matrix alloy, along with using a patented high-energy mixing Mechanical Alloying (MA) process for excellent particle distribution. MA technique continuously mashes the components and breaks apart the mixture of AA2124 powder and ceramic reinforcement under a controlled condition, to produce an intimate and uniform mixture. This process can create high volume fraction of reinforcements with ultrafine particles. Fully dense billet is obtained by hot isostatic pressing (HIP) of the mixture. Billets are then used for direct manufacture to component or fabrication by hot forming processes such as forging and extrusion [23].

Some of the particle-reinforced composites are commercially available in the form of bars. MMC producers use hot extrusion of compacted billets to fabricate the composite bars. The conventional extrusion techniques are used to produce bar which improves the distribution and adhesion of reinforcement particles [9], [24].

Selection of the process route is closely associated with the required properties and the resulting process cost. High strength and high modulus of aluminium MMC are closely linked to particulate size and ceramic loading. Finer particle size effectively contributes to cost reduction in subsequent manufacturing stages such as extrusion and machining. On the flip side, a higher volume percentage of ceramic can adversely impact the wear of the machine tool insert.

The material used in this research was supplied by Materian AMC in Farnborough. Materion AMC has developed a lower cost processing route for manufacturing metal composites via a powder metallurgy route which produces a homogeneous distribution of $\mathrm{SiC}$ within the aluminium matrix. This is achieved with automation of the mechanical alloying process along with significantly increased yield from billet material. HIP process is used to produce the billets which are directly used for hot forging. Figure 2 shows the block diagram of the process.

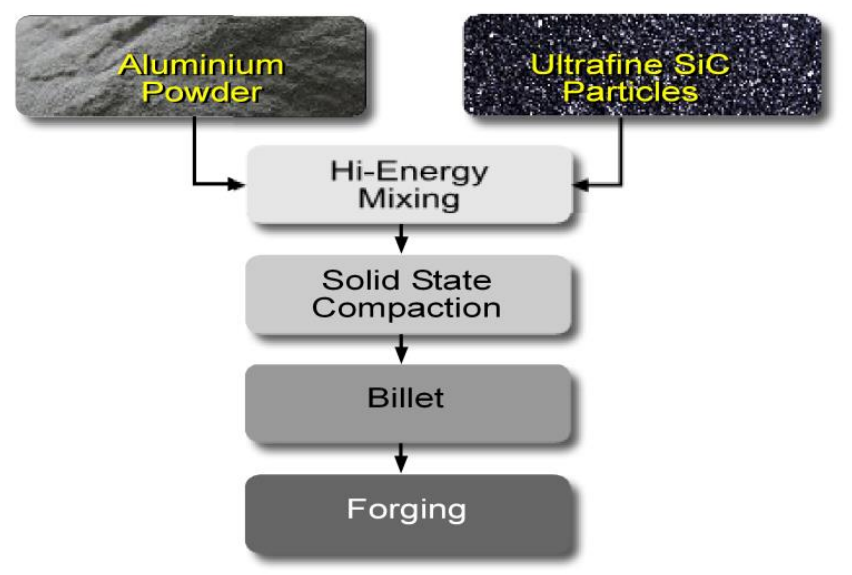

Figure 2. Block diagram of the material process route.

Mechanical testing has proved the mechanical performance of the lower cost route material. Rotating bend fatigue testing was carried out on $2124 / \mathrm{SiC} / 25 \mathrm{p}$ produced using the standard route and the lower cost route. Results of this test shown in Figure 3 indicate that at 315 ${ }^{\circ} \mathrm{C}$ (near the operating temperatures on the piston head) there is negligible difference between the standard route and the lower cost route when the fatigue strength is concerned. Also plotted in Figure 3 is the known data for currently manufactured cast $\mathrm{Al}$ pistons. This indicates a fatigue strength at $1 \times 10^{7}$ cycles of $50 \mathrm{MPa}$, in the case of the $2124 / \mathrm{SiC} / 25 \mathrm{p}$, the fatigue strength at $1 \times 10^{7}$ is $100 \mathrm{MPa}$. This clearly shows the improvement in mechanical performance between the $\mathrm{MMC}$ and the standard cast $\mathrm{Al}$ piston and the potential advantages of using the MMC to manufacture lighter pistons.

The properties of $2124 / \mathrm{SiC} / 25 \mathrm{p}$ and the parent AA2124 alloy are presented in Table 1. 


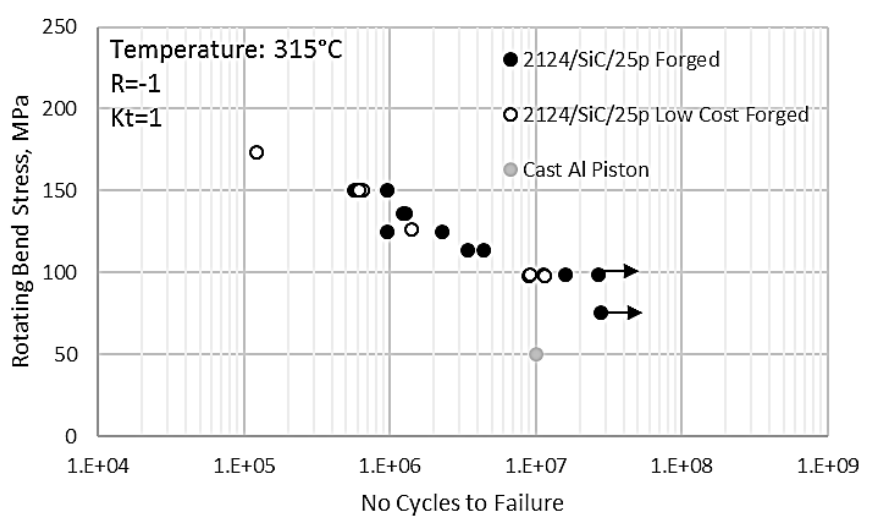

Figure 3. Rotating fatigue test results shows the $2124 / \mathrm{SiC} / 25 \mathrm{p}$ from lower cost route has a very good fatigue strength.

Table 1. Properties of 2124/SiC/25p [25] and AA2124 [26].

\begin{tabular}{|l|l|l|}
\hline Property & $2124 / \mathrm{SiC} / 25 \mathrm{p}$ & AA2124 \\
\hline Young's Modulus & $115 \mathrm{GPa}$ & $73.1 \mathrm{GPa}$ \\
\hline Ultimate Tensile Strength & $680 \mathrm{MPa}$ & $483 \mathrm{MPa}$ \\
\hline $0.2 \%$ Yield Strength & $480 \mathrm{MPa}$ & $441 \mathrm{MPa}$ \\
\hline Poisson's Ratio & 0.3 & 0.33 \\
\hline Elongation to Failure & $5 \%$ & $8 \%$ \\
\hline Thermal Conductivity & $150 \mathrm{~W} / \mathrm{m} /{ }^{\circ} \mathrm{C}$ & $151 \mathrm{~W} / \mathrm{m} /{ }^{\circ} \mathrm{C}$ \\
\hline Thermal Expansion Coefficient & $15.5 \mathrm{ppm} /{ }^{\circ} \mathrm{C}$ & $22.9 \mathrm{ppm} /{ }^{\circ} \mathrm{C}$ \\
\hline Heat Capacity & $0.836 \mathrm{j} / \mathrm{g} /{ }^{\circ} \mathrm{C}$ & $0.882 \mathrm{j} / \mathrm{g} /{ }^{\circ} \mathrm{C}$ \\
\hline Solidus & $548{ }^{\circ} \mathrm{C}$ & $50{ }^{\circ} \mathrm{C}$ \\
\hline Liquidus & $660{ }^{\circ} \mathrm{C}$ & $638^{\circ} \mathrm{C}$ \\
\hline Density & $2.88 \mathrm{~g} / \mathrm{cm}^{3}$ & $2.78 \mathrm{~g} / \mathrm{cm}^{3}$ \\
\hline Vickers Hardness & 210 & 146 \\
\hline Average particle size & $3 \mu \mathrm{m}$ & $\mathrm{n} / \mathrm{a}$ \\
\hline
\end{tabular}

\section{Forging Processes}

In forging processes transfer of heat between the die and the workpiece results in thermal gradients in the workpiece, which causes a non-uniform plastic flow. This is called die chilling. Using the glass lubricant coating for the billets can create a thermal shield that partially helps to diminish this effect. In practice, forging dies are heated to reduce the chilling effect. Using fast-acting forging machines that have a short die-billet contact time, such as screw presses is another way of reducing this effect.

Heating the dies to the same temperature as the workpiece can completely remove the chilling effect, this is called isothermal forging. Aluminium alloys are usually forged using hydraulic presses under isothermal or near isothermal conditions at temperatures that do not significantly compromise the strength or hardness of the die material. The primary advantages of isothermal forging are achieving closer part tolerances, saving material and cost of subsequent machining. There may also be a reduction in tooling cost due to the slow process which needs lower forging pressures. However, more expensive die material and controllable die heating systems are required.

Page 3 of 9
Alternatively, fast-acting screw presses deliver a high speed forging blow to reduce the contact time. Screw presses provide flexibility and control over a wide energy range, and their higher forging pressures make them suitable for the precision forging of a wide variety of parts. Screw presses have high repeatable accuracy and short cycle times that enhance productivity.

In this research both, hydraulic press isothermal forging and screw press hot forging of the piston were modelled using finite element method. The influence of forging parameters such as ram speed and billet temperature was studied to understand process response and material flow.

The geometry of the piston and its forged form (forging) are shown in Figure $4 \mathrm{a}$ and $4 \mathrm{~b}$, respectively. In order to create geometry suitable for forging some of the features such as boss pin holes and ring grooves have been removed and extra material added for post-forging machining. The forged form was used to design the punch and die geometry. The goal was to achieve near net shape forging including the crown feature on the piston head that could save material and machining cost. To achieve that, the modelling was first completed with flat piston head to grasp an overview of the process, and later simulation of forging the piston with the crown details was carried out. Parameters describing forging condition on both presses are shown in Table 2.
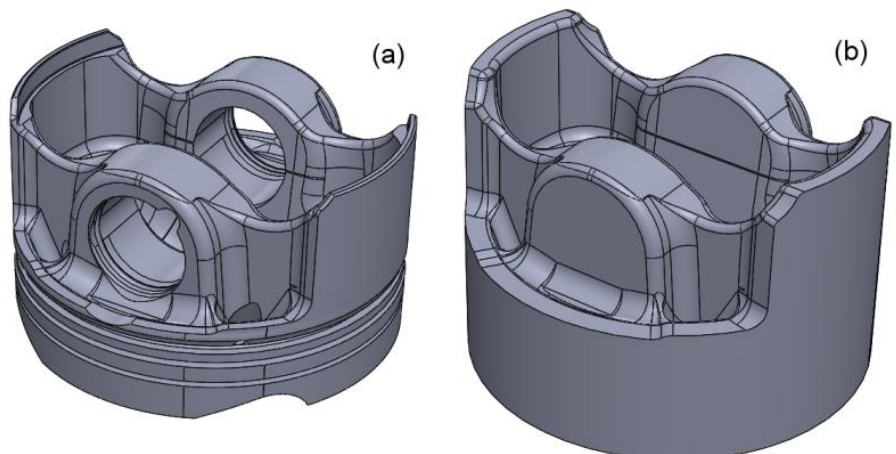

Figure 4. The geometry of (a) actual piston and (b) piston without the crown features for forging.

Table 2. Parameters of forging processes assumed in the FE models

\begin{tabular}{|l|l|l|}
\cline { 2 - 3 } \multicolumn{1}{c|}{} & Parameter & Set value \\
\hline \multirow{4}{*}{ Lydraulic press } & Initial Billet temperature & $470{ }^{\circ} \mathrm{C}$ \\
\cline { 2 - 3 } & Punch and die temperature & $470{ }^{\circ} \mathrm{C}$ \\
\cline { 2 - 3 } & Ram velocity & $5 \mathrm{~mm} / \mathrm{s}$ \\
\cline { 2 - 3 } Screw press & Process time & $5.01 \mathrm{~s}$ \\
\hline \multirow{3}{*}{ High strain rate } & Initial billet temperature & $400{ }^{\circ} \mathrm{C}$ \\
\cline { 2 - 3 } & Punch and die temperature & $250{ }^{\circ} \mathrm{C}$ \\
\cline { 2 - 3 } & Press energy & $34 \mathrm{~kJ}$ \\
\cline { 2 - 3 } & $\begin{array}{l}\text { Initial ram velocity } \\
\text { corresponding to set energy }\end{array}$ & $270 \mathrm{~mm} / \mathrm{s}$ \\
\hline Billet & Cylindrical & $\varnothing 41.5 \times 35.83 \mathrm{~mm}$ \\
\hline
\end{tabular}

\section{FE simulation}

FE modelling of the forging processes has been carried out using the commercial DEFORM 3D V11.02 software. Full 3D models of the 
processes were developed. The composite was modelled as a rigidplastic, isotropic, Huber-Mises material with flow stress depending on temperature, strain and strain rate. The flow stress data was derived from the compression test carried out on Zwick mechanical testing hydraulic press at low strain rates of 0.01 and $0.1 \mathrm{~s}^{-1}$, and on a Gleeble machine at strain rates of 1,10,100 and $250 \mathrm{~s}^{-1}$. These tests were carried out at $350,400,450$ and $500{ }^{\circ} \mathrm{C}$. Cylindrical test specimens used in the compression test had a diameter of $10 \mathrm{~mm}$ and were $15 \mathrm{~mm}$ high. Figure 5 shows flow stress curves derived in the tests carried out at $350{ }^{\circ} \mathrm{C}$ and $500{ }^{\circ} \mathrm{C}$ and the strain rate of 1,10 and $250 \mathrm{~s}^{-1}$. The flow stress at $350{ }^{\circ} \mathrm{C}$ was much higher than at $500{ }^{\circ} \mathrm{C}$, and that its magnitude increased significantly at higher strain rates.

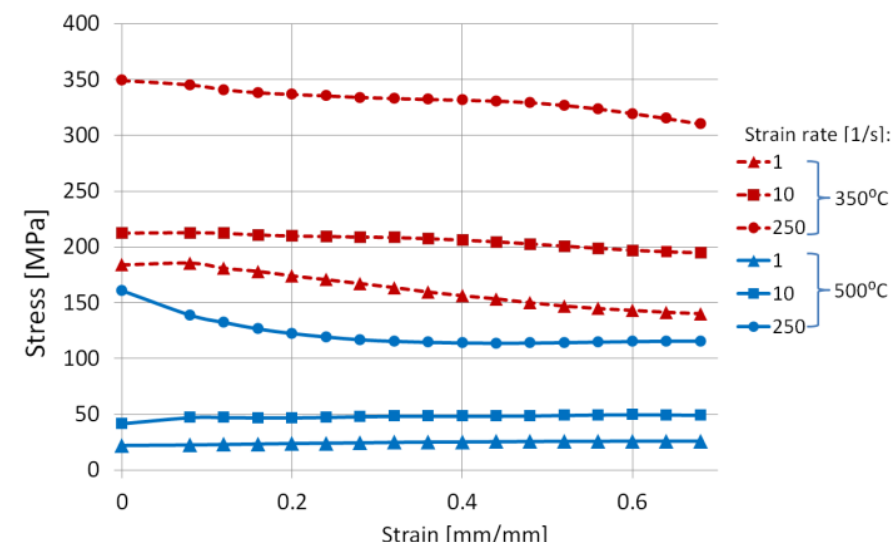

Figure 5. Flow stress curves at different temperature and strain rates used in FE simulation

The punch was assumed to be elastic to enable computation of die wear simultaneously with the material deformation while the die was held a rigid surface with no mesh. This significantly reduced the computational time and cost. The die and the punch are assumed to be made from $\mathrm{H} 13$ tool steel and properties of this steel available in the DEFORM material library were assigned to these tools.

Both the billet and the punch were auto-meshed using eight-node hexahedral elements. The billet was meshed with 128852 elements while the punch with 16500 elements. Regional mesh refinements in the critical areas were implemented in the workpiece by using several box windows with small size factors. Automatic remeshing was applied during simulation when distortion of element reached a threshold.

Friction at the material-die interface was described using the Zibel friction law with a constant friction factor of 0.4 in accordance with [27]. Thermal properties of $2124 / \mathrm{SiC} / 25 \mathrm{p}$ were taken from [25]. The contact heat transfer coefficient was assumed to be constant and set to $11 \mathrm{~kW} \cdot \mathrm{m}^{-2} \cdot \mathrm{K}^{-1}$ [27]. Other parameters of the processes (temperature of billet, punch and die, the velocity of the hydraulic ram and screw press energy) were set as shown in Table 2. Figure 6 shows the cross-section of the FE model of the tools and billet assembly.

It was assumed that abrasive wear was a dominant wear mechanism. Wear of the punch was predicted using a module dedicated to this problem and embedded into DEFORM 3D V11.02 software. The module uses the tool wear model proposed by Archard:

$$
W=\int K \frac{p^{a} v^{b}}{H^{c}} d t
$$

Where,

$W=$ die wear

$p=$ interface pressure,

$v=$ material sliding velocity,

$H=$ tool material hardness at forging temperature

$K=$ material constant

$a, b$, and $c$ are constants

The value of $\mathrm{K}$ was set to $1 \times 10^{-5}$, while $\mathrm{a}, \mathrm{b}$ and $\mathrm{c}$ for tool steel are assumed to be 1, 1 and 2, respectively. Hardness $\mathrm{H}$ of the $\mathrm{H} 13$ tool steel was taken from [28].

Additionally, for the process modelled under hydraulic press condition, a sensitivity analysis was carried to investigate the effects of temperature and ram speed on material flow, stresses in the die and forging force.

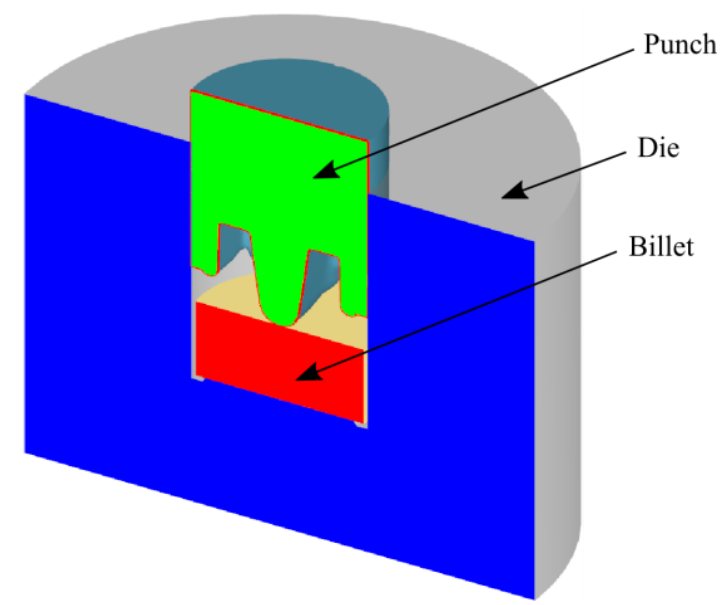

Figure 6. Schematic of tool set and workpiece in FEA simulation

\section{Results}

\section{Forging without the crown features}

Figure 7 shows the deformation of the billet as the forging process progressed. The forming process began with the punch being pushed into the billets and free flowing of material into punch cavities. The forging load slowly increased with the punch stroke. When the material got in contact with the surfaces of cavities friction restricted material flow which was reflected in a steeper increase of the forging load. As the filling of the cavities progressed pressure built up and a steep increase in the forging load is observed. Eventually, the excess of material flew into the flash that created a further flow resistance causing the sudden increase of the forging load.

The type of press selected for forging significantly influenced the forging load and required energy. Evolution of the forging load for both presses is shown in Figure 8. It is obvious that a much higher load was required to forge piston on the screw press. This is due to strain rate sensitivity of the material (Figure 5). Consequently, this translates to a much higher energy requirement for forging the piston on the screw press as illustrated in Figure 9. 

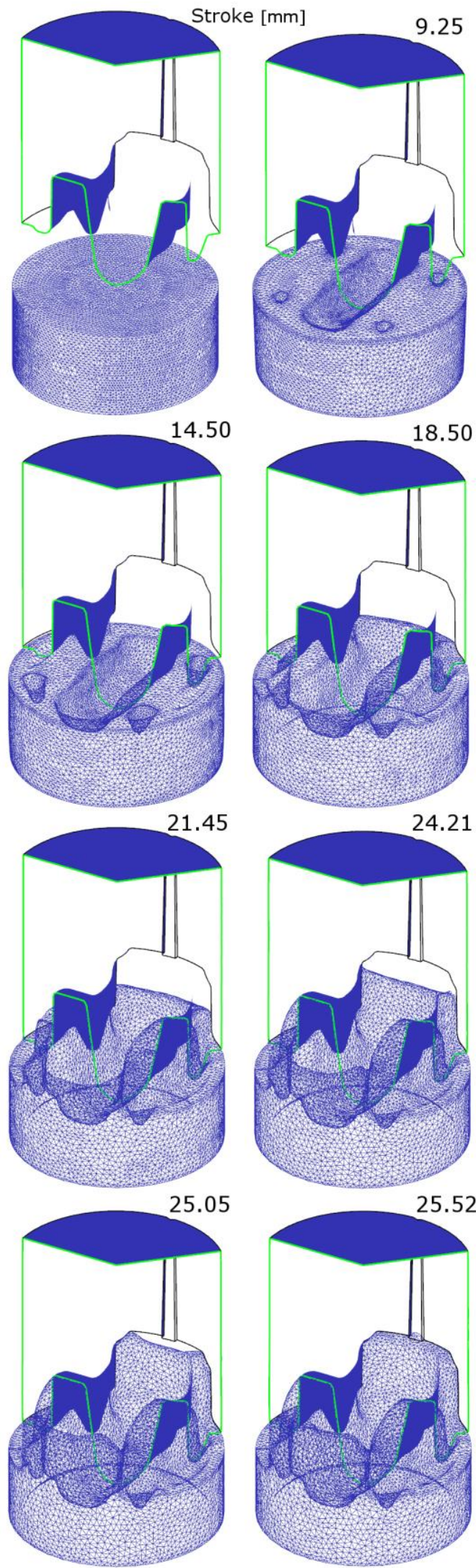

Figure 7. Progression of the forging process as the punch moves down. Punch is sectioned for a clearer display of the material flow into the cavity.

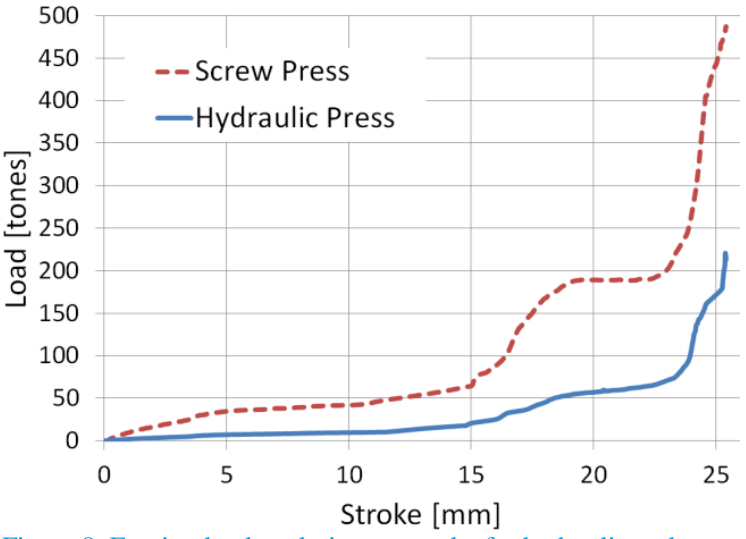

Figure 8. Forging load evolution vs. stroke for hydraulic and screw press.

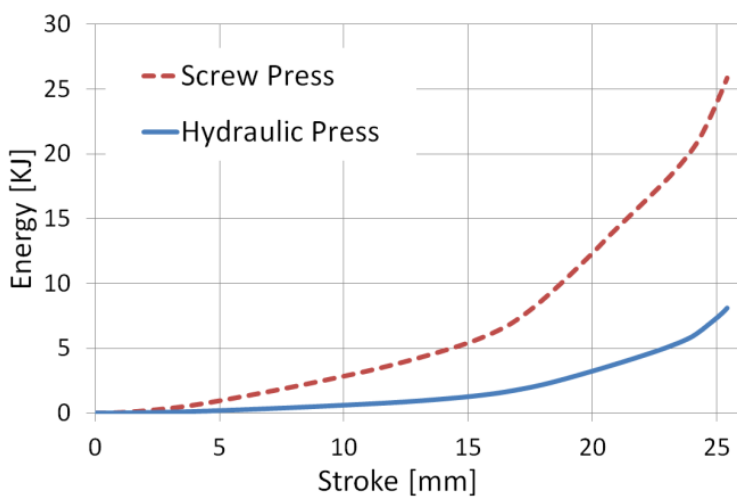

Figure 9. Energy vs. stroke for forging process.

Figure 10 shows distributions of effective strain, strain rate, effective stress and temperature in the pistons at the final stage of forging in both presses. The effective strain depends mainly on the changes in the shape thus the effective strains was similar in both presses. The average strain rate was 100 times higher in the piston forged on the screw press compared with that of on the hydraulic press. As a result, the effective stresses in the piston forged on the screw press were also higher; more than four times and reached $250 \mathrm{MPa}$. In the piston forged on the hydraulic press, these didn't exceed $60 \mathrm{MPa}$. As for temperature, in the piston forged on the hydraulic press only a slight temperature rise $\left(\max 20^{\circ} \mathrm{C}\right)$ was observed. On the contrary, the material forged on the screw press experienced a high adiabatic heating due to the high strain rate deformation and friction. In the webs, the temperature increased to $650{ }^{\circ} \mathrm{C}$. This indicated that under screw press conditions the material was susceptible to incipient melting which should be avoided. The chilling effect of the die (this was heated to $250^{\circ} \mathrm{C}$ ) was also observed. As a result, a hightemperature gradient $\left(376^{\circ} \mathrm{C}\right.$ to $\left.650{ }^{\circ} \mathrm{C}\right)$ was created across the piston.

Summarising, the isothermal forging with relatively uniform temperature and low strain rates, resulted in a more homogeneous metal flow and lower stresses in the material. As a result, the material is less prone to forging defects. To understand the influence of various parameters on forging of $2124 / \mathrm{SiC} / 25 \mathrm{p}$ a sensitivity analysis was conducted for both processes. 

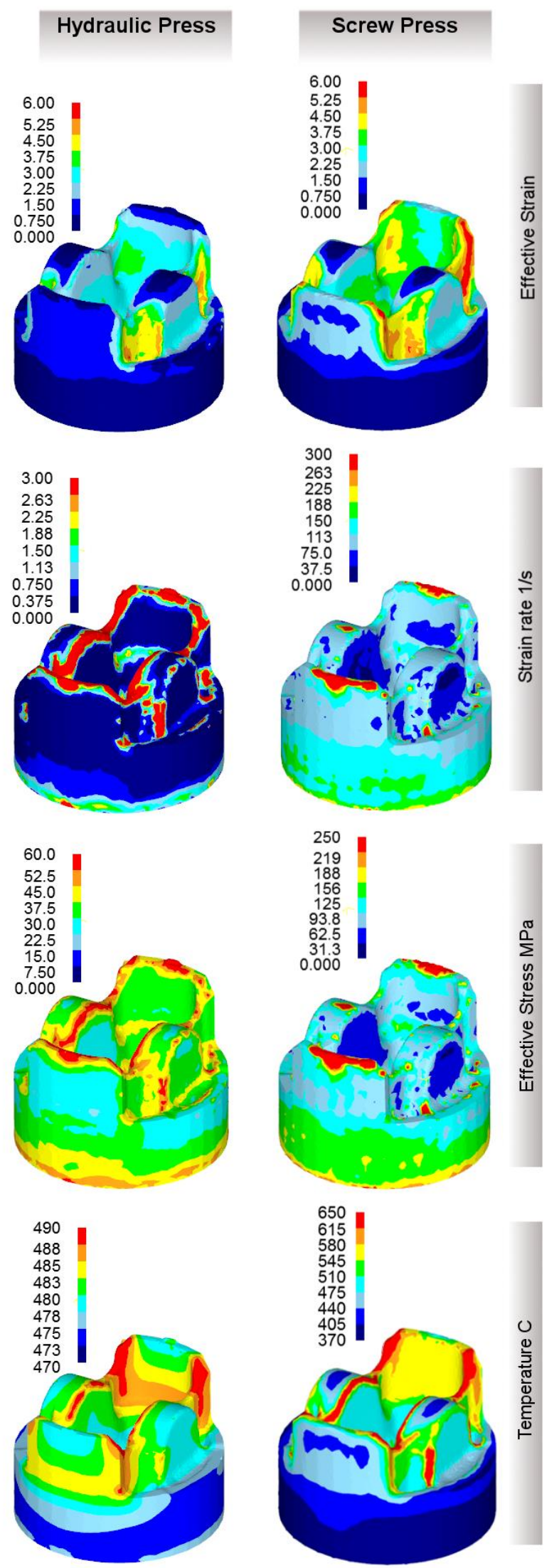

Figure 10. Distribution of effective strain, strain rate, effective stress and temperature at the end of the forging under the hydraulic press and screw press conditions.

\section{Sensitivity analysis}

For the isothermal process on the hydraulic press, the variation of the final forging load and temperature distribution in the billet were analysed for different ram velocities of 1,5 and $10 \mathrm{~mm} / \mathrm{s}$ and three temperatures of the billet 430,450 and $470{ }^{\circ} \mathrm{C}$. Figure 11 shows the respective graphs of load variation with the punch stroke obtained in this analysis. The ram velocity, within the investigated range, had a minor impact on the forging load. However, a slightly higher forging load was obtained for the ram velocity of 10 and $5 \mathrm{~mm} / \mathrm{s}$ which was associated with the higher strain rate in comparison with that in forging carried out with the ram velocity of $1 \mathrm{~mm} / \mathrm{s}$. Faster 10 and 5 times ram speeds resulted in the higher strain rates causing the flow stress to become larger; accordingly, the load and energy used to deform material ramped up also. This was reflected in the temperature distribution within the pistons; energy used to deform material is converted into heat. Figure 12 shows histograms of temperature in the pistons at the end of the process carried out with these three ram velocities and for the same $470{ }^{\circ} \mathrm{C}$ initial temperature of the billet

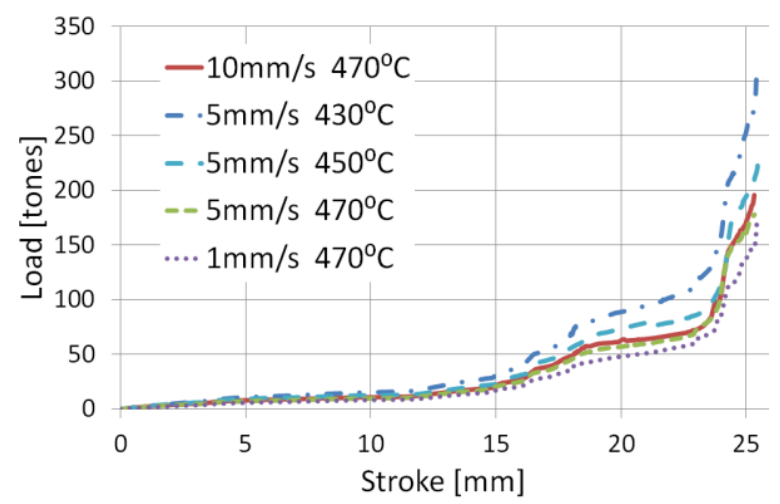

Figure 11. Load vs. stroke for isothermal forging at various ram velocities and billet temperatures.

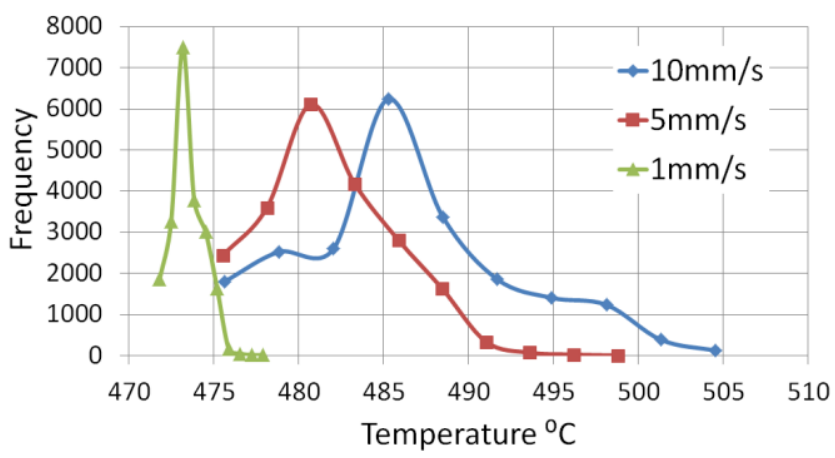

Figure 12. The frequency of temperatures across the material at the end of isothermal forging at $470{ }^{\circ} \mathrm{C}$ for different ram speeds.

Forging on the screw press was also studied under various temperatures, namely 350,400 and $450{ }^{\circ} \mathrm{C}$, with the aim to understand how the temperature rise during forging could be controlled. In this analysis, the pressing energy was set to the same energy of $34 \mathrm{KJ}$ in all models, so the initial ram velocity was the same in all three processes. The changes in the ram velocity and consequently the strain rate depended on material resistance to the deformation which in turn depended on the billet temperature. Therefore, the resulting load and energy used (converted into heat 
generated in the forged material) were a function of the initial temperature and instantaneous ram velocity. Figure 13 shows the final forging load versus the range of temperature in the piston with different initial billet temperature (marked with red diamonds) at the end of forging. The highest temperature was obtained in the billet with the initial temperature of $400{ }^{\circ} \mathrm{C}$ while the lowest in the billet with an initial temperature of $450{ }^{\circ} \mathrm{C}$. The results show that the resistance to deformation (flow stress) had a more significant influence on the maximum temperature than the initial billet temperature. However, results obtain for $350{ }^{\circ} \mathrm{C}$ and $400{ }^{\circ} \mathrm{C}$ indicate that it is not always the case and both factors have to be taken into account when the forging parameters are defined. In all cases, the maximum temperature was higher than the solidus temperature so incipient melting can take place when the piston is forged on the screw press.

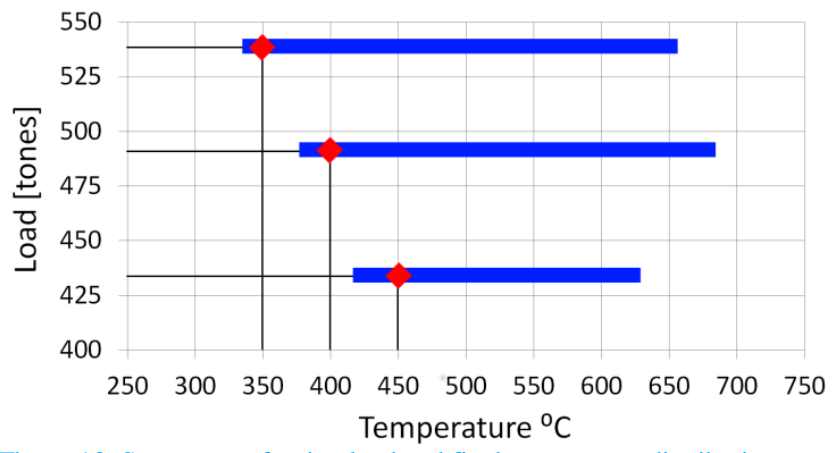

Figure 13. Screw press forging load and final temperature distribution to initial billet temperature (indicated by diamonds).

\section{Die wear and tool life}

The tool life is a crucial factor in the manufacturing process cost assessment thus a prediction of die wear is important. In the absence of experimentally assessed constants in Equation 1 used to compute the die wear, only a comparative assessment of the wear on the presses was possible. Further, the wear analysis was carried out for the punch only as this tool was more prone to wear than the die.

Results of analysis, normal pressure and computed die wear are shown in Figure 14. The punch wear is expressed in millimetres of the punch material removed in one forging operation. As expected, the wear was higher in the process carried out on the screw press and was equal to $3.6 \times 10^{-5} \mathrm{~mm}$ while during forging on the hydraulic press was $1.5 \times 10^{-5} \mathrm{~mm}$. The wear of punch on screw press would be more than twice as that of the hydraulic press. This is a combined effect of the higher normal pressure on the tool as depicted in Figure 14 and the higher material sliding velocity on the tool surface. Lower tool life is the result of higher stresses and sliding velocity and change in tool hardness due to heating during forging.

\section{Near net shape forging with the crown features}

The analysis described above was complemented with the simulation of the piston with the crown features on the back face. Figure 15 illustrates the cross-sectional view of the both pistons. It is clear that forging pistons with the crown features can save material and machining costs.
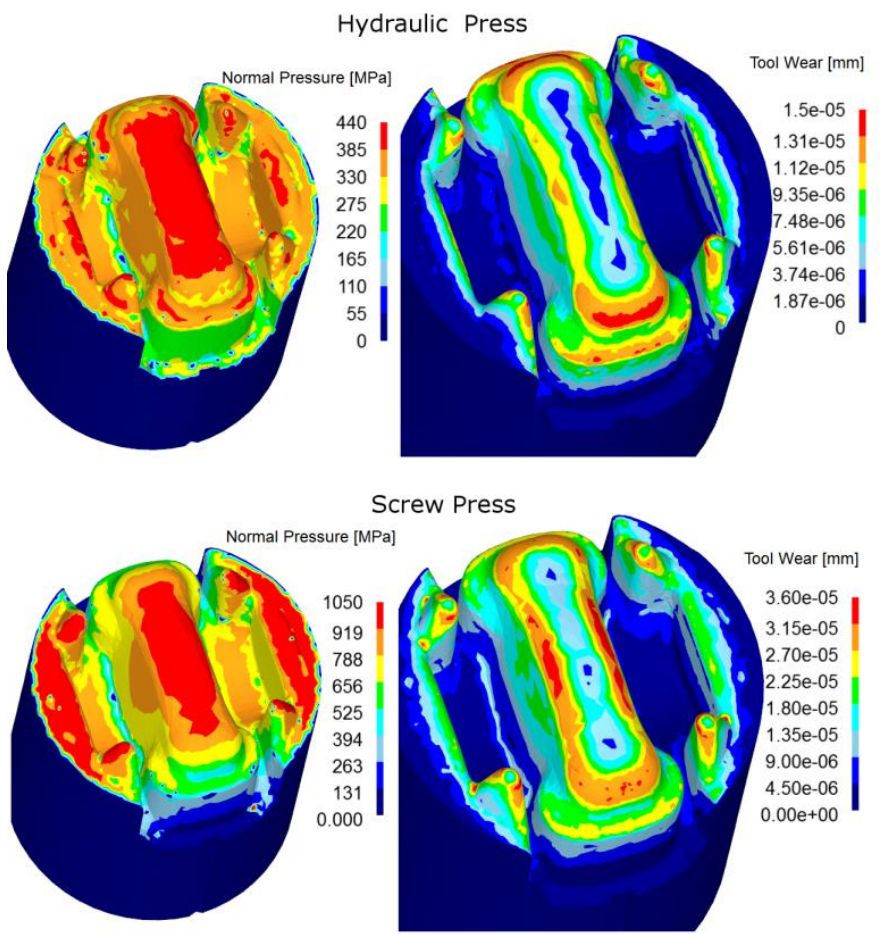

Figure 14. Contact pressure and piston wear for forging process carried out on (a) hydraulic press, (b) screw press. (a)

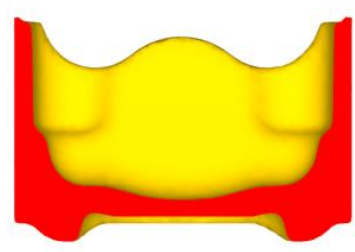

(b)

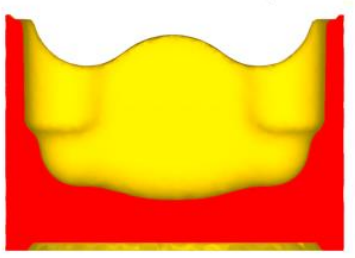

Figure 15. A cross-sectional view of piston and piston head, (a) with crown features, (b) flat.
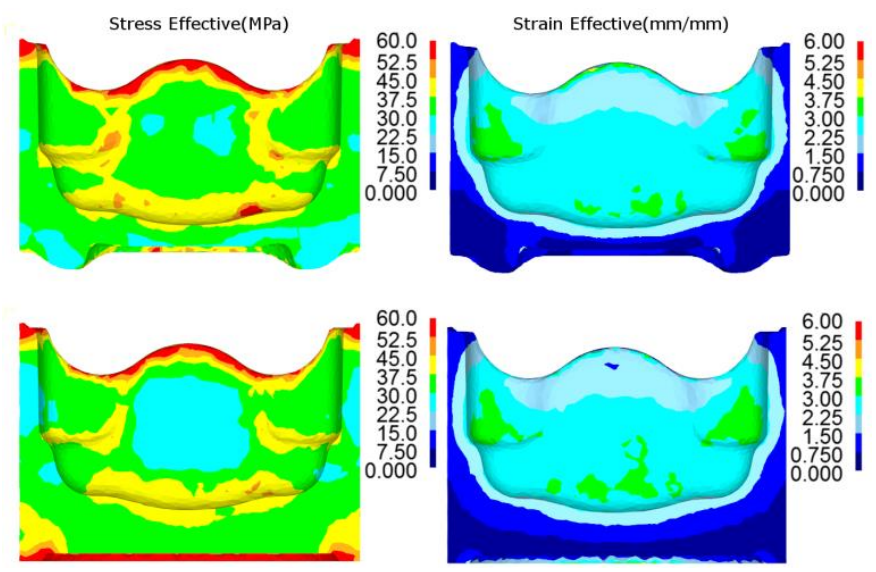

Figure 16. Comparison of effective stress and strain in the piston with and without crown features; both forged on the hydraulic press.

The FE results showed that the presence of the crown features didn't have a significant impact on the forging process. The distributions of effective stress and strain are used to compare these two processes. Figure 16 shows the results for both piston geometries forged on the hydraulic press. Similar distributions are obtained, meaning that adding additional features had an insignificant effect on the material 
flow. A similar conclusion can be drawn from the results of simulation for the screw press which is presented Figure 17.
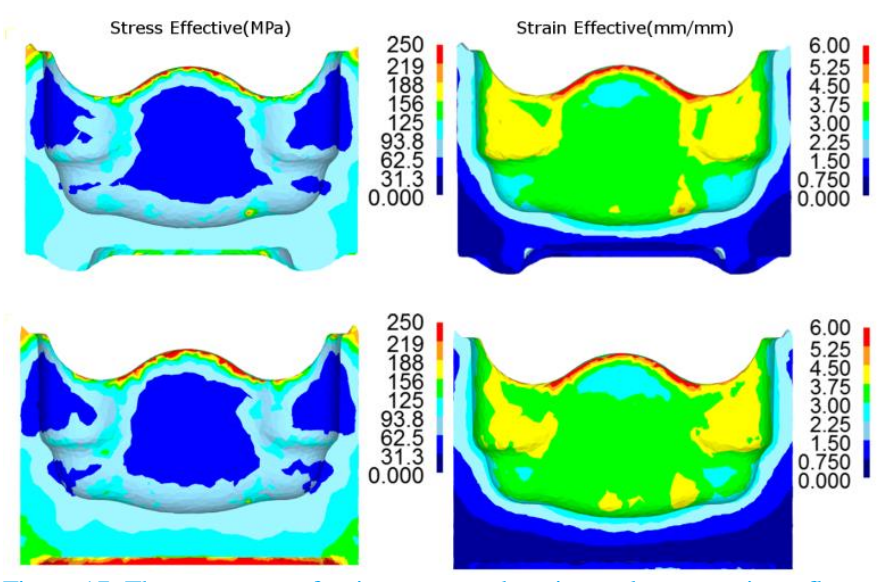

Figure 17. The screw press forging stress and strain results comparison, flat piston head Vs piston with crown features.

\section{Summary/Conclusions}

This paper presents results of the study of the precision forging of an automotive piston from $2124 / \mathrm{SiC} / 25$ p metal matrix composite. The study was carried out using finite element simulations. The aim was to get a better insight into the practical aspects associated with the forging process carried out under different forging conditions; isothermal forging on a hydraulic press and hot forging on a screw press. Flow stress curves of the composite used in the simulation were derived from the compression test carried out at five strain rates $\left(1,10,100\right.$ and $\left.250 \mathrm{~s}^{-1}\right)$ and four temperatures $(350,400,450$ and $\left.500{ }^{\circ} \mathrm{C}\right)$. The key process variables in the simulation were the initial billet temperature and ram velocity. The following conclusions can be drawn:

- Piston isothermally forged on the hydraulic press showed more uniform temperature distribution and lower stresses. Under this condition, the material is less prone to forging defects.

- Forging on the screw press induced in the material much higher stress due to higher strain rate. More energy was required to deform material leading to the adiabatic heating and a significant temperature rise. Without attention to a complex interaction between flow stress, temperature and strain rate there is a potential for incipient melting during forging. The numerical simulation carried out for three different initial billets temperatures showed that by increasing the initial billet temperate from $400{ }^{\circ} \mathrm{C}$ to $450{ }^{\circ} \mathrm{C}$ reduced the maximum temperature in the forged piston. However, both factors, temperature and flow stress, have to be taken into account when the forging parameters are defined to find the optimal conditions.

- Comparative wear analysis of the punch showed that its wear would be more than twice of that on the hydraulic press. Since the wear depends on contact pressure, sliding velocity and tool steel hardness it can be controlled to some extent by process parameters. Increasing forging temperature would lower flows stress and consequently contact pressure. Further, the press could be set to the lower energy which means lower ram velocity and lower sliding velocity. The life could be extended by selecting a harder tool material but this could inevitably increase the cost.

- FE modelling of the metal composite piston showed that it is possible to obtain a forging in which the back face of the piston does not require machining, significantly reducing machining costs further down the process route. This net shape forging option for the back face can be extended to the crown and this is the focus of ongoing work to produce net shape pistons and further reduce material and machining costs.

\section{References}

1. Miracle DB. Metal matrix composites - From science to technological significance. Compos Sci Technol. 2005;65(15-16 SPEC. ISS.):2526-2540. doi:10.1016/j.compscitech.2005.05.027.

2. Chawla N, Chawla KK. Metal-matrix composites in ground transportation. JOM. 2006;58(11):67-70.

3. Limited AMC. AMC225XE particle reinforced aluminium alloy. :3-8. www.amc-mmc.co.uk.

4. Rosso M. Ceramic and metal matrix composites: Routes and properties. J Mater Process Technol. 2006;175(1-3):364-375. doi:10.1016/j.jmatprotec.2005.04.038.

5. Martín E, Forn A, Nogué R. Strain hardening behaviour and temperature effect on Al-2124/SiCp. J Mater Process Technol. 2003;143-144(1):1-4. doi:10.1016/S0924-0136(03)00292-9.

6. Bruzzi MS, McHugh PE, O’Rourke F, Linder T. Micromechanical modelling of the static and cyclic loading of an Al 2124-SiC MMC. Int J Plast. 2001;17(4):565-599. doi:10.1016/S0749-6419(00)00063-2.

7. Smaga M, Walther F, Eifler D. Monotonic and cyclic deformation behaviour of the $\mathrm{SiC}$ particle-reinforced aluminium matrix composite AMC225xe. Adv Eng Mater. 2010;12(4):262268. doi:10.1002/adem.200900345.

8. Karamiş MB, Alper Cerit A, Selçuk B, Nair F. The effects of different ceramics size and volume fraction on wear behavior of Al matrix composites (for automobile cam material). Wear. 2012;289:73-81. doi:10.1016/j.wear.2012.04.012.

9. Hashiguchi D, Tricker D, Tarrant A, Campbell J, Pokross C. Discontinuously reinforced aluminum MMC extrusions. Met Powder Rep. 2016;0(0):1-7. doi:10.1016/j.mprp.2016.01.074.

10. Narayan S, Rajeshkannan A. Workability Behavior of Powder Metallurgy Carbide Reinforced Aluminum Composites during Hot Forging. Mater Manuf Process. 2015;6914(August 2016):37-41. doi:10.1080/10426914.2015.1004703.

11. Özdemir İ, Cöcen Ü, Önel K. The effect of forging on the properties of particulate-SiC-reinforced aluminium-alloy composites. Compos Sci Technol. 2000;60(3):411-419. doi:10.1016/S0266-3538(99)00140-2.

12. Badini C, Vecchia GM La, Fino P, Valente T. Forging of 2124 / $\mathrm{SiC} \mathrm{p}$ composite : preliminary studies of the effects on microstructure and strength. 2001;116.

13. Cavaliere P. Flow curve prediction of an Al-MMC under hot working conditions using neural networks. Comput Mater Sci. 2007;38(4):722-726. doi:10.1016/j.commatsci.2006.05.002.

14. Vecchia GM La, D'errico F. Fracture mechanics behaviour of aluminium matrix composites reinforced with SiC. Int J Mater Prod Technol. 2002;17(3-4):261-274.

15. Ozden S, Ekici R, Nair F. Investigation of impact behaviour of aluminium based $\mathrm{SiC}$ particle reinforced metal-matrix composites. Compos Part A Appl Sci Manuf. 2007;38(2):484494. doi:10.1016/j.compositesa.2006.02.026. 
16. Li Y, Ramesh KT, Chin ESC. Plastic Deformation and Failure in A359 Aluminum and an A359-SiCp MMC under Quasistatic and High-strain-rate Tension. J Compos Mater. 2006;41(1):27-40. doi:10.1177/0021998306063351.

17. Kalaichelvi V, Sivakumar D, Karthikeyan R, Palanikumar K. Prediction of the flow stress of $6061 \mathrm{Al}-15 \% \mathrm{SiC}-\mathrm{MMC}$ composites using adaptive network based fuzzy inference system. Mater Des. 2009;30(4):1362-1370. doi:10.1016/j.matdes.2008.06.022.

18. Zhang H, Chen MW, Ramesh KT, Ye J, Schoenung JM, Chin ESC. Tensile behavior and dynamic failure of aluminum 6092/B4C composites. Mater Sci Eng A. 2006;433(1-2):70-82. doi:10.1016/j.msea.2006.06.055.

19. Kuhlman GW. Forging of Aluminum Alloys. 2013.

20. Natarajan N, Vijayarangan S, Rajendran I. Wear behaviour of A356/25SiC p aluminium matrix composites sliding against automobile friction material. Wear. 2006;261(7):812-822.

21. Karamiş MB, Nair F. Effects of reinforcement particle size in MMCs on extrusion die wear. Wear. 2008;265(11-12):17411750. doi:10.1016/j.wear.2008.04.044.

22. Nair F, Karamis MB. An investigation of the tribological interaction between die damage and billet deformation during MMC extrusion. Tribol Int. 2010;43(1-2):347-355. doi:10.1016/j.triboint.2009.06.018.

23. Singh AR, Sharma PK. Design and Analysis of Reinforced Aluminium Alloy-AMC225XE Connecting Rod using FEA. 2013;2(11):2737-2743.

24. Goswami RK, Sikand R, Dhar A, Grover OP, Jindal UC, Gupta AK. Extrusion characteristics of aluminium alloy/SiCp metal matrix composites. Mater Sci Technol. 1999;15(4):443-449.

25. Evans A, San Marchi C, Mortensen A. Metal Matrix Composites in Industry: An Introduction and a Survey. Springer Science \& Business Media; 2013.

26. Aerospace Specification Metals Inc. Aluminum 2124-T851. http://asm.matweb.com/search/SpecificMaterial.asp?bassnum. Accessed August 30, 2016.

27. System_Documentation_V11.02 D. Scientific Forming Technologies Corporation. Sci Form Technol Corp Columbus OH. 2015.

28. Benedyk JC. Aerospace And High Performance Alloys Database. UNE. 36072:2.

\section{Contact Information}

Corresponding author: Javad Falsafi (javad.falsafi@strath.ac.uk), Advanced Forming Research Centre, University of Strathclyde, 85 Inchinnan Drive, Inchinnan, Renfrew PA4 9LJ.

\section{Acknowledgments}

The authors would like to gratefully thank Andrew Tarrant and Stuart Godfrey from Materion AMC for the constructive comments and recommendations.

\section{Definitions/Abbreviations}

MMC

PM

HIP

MA

EDM
Metal Matrix Composite

Powder Metallurgy

Hot Isostatic Pressing

Mechanical Alloying

Electrical Discharge

Machining

Page 9 of 9 